\title{
Fast Frequency Response from Energy Storage Systems - A Review of Grid Standards, Projects and Technical Issues
}

\author{
Lexuan Meng, Jawwad Zafar, Shafi K. Khadem, Alan Collinson,
}

Kyle C. Murchie, Federico Coffele, Graeme Burt

1

\begin{abstract}
Electric power systems foresee challenges in stability due to the high penetration of power electronics interfaced renewable energy sources. The value of energy storage systems (ESS) to provide fast frequency response has been more and more recognized. Although the development of energy storage technologies has made ESSs technically feasible to be integrated in larger scale with required performance, the policies, grid codes and economic issues are still presenting barriers for wider application and investment. Recent years, a few regions and countries have designed new services to meet the upcoming grid challenges. A number of grid-scale ESS projects are also implemented aiming to trial performance, demonstrate values, and gain experience. This paper makes a review on the above mentioned aspects, including the emerging frequency regulation services, updated grid codes and grid-scale ESS projects. Some key technical issues are also discussed and prospects are outlined.
\end{abstract}

Index Terms--frequency response, energy storage, grid code.

\section{NOMENCLATURE}

$\begin{array}{ll}\text { ACE } & \text { Area Control Error } \\ \text { ACS } & \text { Area Correction Signal } \\ \text { AGC } & \text { Automatic Generation Control } \\ \text { BA } & \text { Balancing Authority } \\ \text { DG } & \text { Distributed Generator } \\ \text { DNO } & \text { Distribution Network Operator } \\ \text { EFR } & \text { Enhanced Frequency Response }\end{array}$

ENTSO-E European Network of Transmission System Operators for Electricity

EPS Electric Power System

ESS Energy Storage System

FERC Federal Energy Regulatory Commission

FFR Fast Frequency Response

FFR-AUS Fast Frequency Response of Australia

FFR-IR Fast Frequency Response of Ireland

GIR Grid Interconnection Requirement

HVDC High Voltage Direct Current

IEEE Institute of Electrical and Electronics Engineers

MMC Modular Multi-level Converter

NERC North America Electric Reliability Corporation

NC-RfG Network Code on Requirements for Grid Connection of Generators

\author{
OLTC On-Load-Tap-Changers \\ PFR Primary Frequency Response \\ PPM Power Park Module \\ RegA Regulation A of PJM \\ RegD Regulation D of PJM \\ ROCOF Rate-Of-Change-Of-Frequency \\ SIR Synchronous Inertia Response \\ SNS Smarter Network Storage \\ SOF System Operability Framework \\ SOP System Operation Practice \\ SoC State-of-Charge \\ STATCOM Static Compensator \\ UKPN UK Power Networks
}

\section{INTRODUCTION}

—XCESSIVE carbon emissions and fossil fuels based energy resources are the main concerns for energy system development since 90 s of last century. Power sector is certainly the major consumer of such resources. Expectations come to the mass utilization of renewable energy resources (RES) to substitute conventional generation.

However, the fluctuating and intermittent characteristics of most RES cause critical issues in electric power system (EPS) for power balancing, stability and system level regulation. Moreover, the electrification of other energy sectors, e.g. transport and heating, brings potential of congestion in EPS in near future. Enhancing the flexibility of the power sector can significantly reduce overall cost and improve system performance, thus providing possibility to accommodate more RES and consumers. Major flexibility solutions include [1]-[3]: i) flexible generation to ensure back-up capacity, ii) greater interconnection to systems beyond the region, iii) enabling demand to respond more to short-term price signals, and iv) increased electrical energy storage systems (ESS).

From grid stability point of view, frequency dynamics and stability are the key measures which indicate the strength of the grid as well as the balance condition between generation and demand. Grid frequency control is facing key challenges under high penetration of non-synchronous generation [4]. Although few large international jurisdictions are experiencing high rate-

Lexuan Meng, Jawwad Zafar, Federico Coffele and Graeme Burt are with Power Networks Demonstration Center, University of Strathclyde, Glasgow, UK (Emails: lexuan.meng@gmail.com, jawwad.zafar@strath.ac.uk, federico.coffele@strath.ac.uk, and Graeme.Burt@strath.ac.uk).

Shafi K. Khadem is with International Energy Research Centre, Tyndall National Institute, Ireland (Email: shafi.khadem@ierc.ie).

Alan Collinson is with Scottish Power Energy Networks, UK (Email: Alan.Collinson@ spenergynetworks.co.uk).

Kyle C. Murchie is with Scottish and Southern Electricity Networks, UK. (Email: kyle.c.murchie@sse.com) 
of-change-of-frequency (ROCOF) issues, Ireland and UK are exceptions due to their relative smaller size and limited interconnection with continental grids. Both Ireland and UK have emerging concerns for high ROCOF (>0.5 Hz/s) [5]. The System Operability Framework (SOF) in UK assessed the evolving system inertia trend which indicated an increasing risk of high ROCOF especially under the "Gone Green" future energy scenario [6]. These challenges require the grid to equip with new capabilities, such as ROCOF mitigation, inertia enhancement, over-frequency generation shedding scheme, frequency response to large disturbances, and so on.

Driven by the challenges mentioned above, grid-scale ESS is a promising solution finding applications in domestic, industrial and commercial circumstances [7]-[9]. Although there still are economic, regulatory and technical barriers preventing the wide adoption of grid-scale ESS, there has been active development and grid code adaptation appear for ESS application in recent years [7], [9]-[11]. New frequency regulation services are emerging aiming to take full utilization of the ESS advantages. The major task of this paper is to review the existing grid connection requirements applicable to ESSs, as well as the emerging frequency response services demanding fast responses, with a special focus on transmission level applications.

\section{FREQUENCY RESPONSE AND DESIGN CONSIDERATIONS}

A nominal frequency is set in AC electric power systems, i.e. $60 \mathrm{~Hz}$ in North America and $50 \mathrm{~Hz}$ in Europe and China. The frequency has to be maintained within a limited range by keeping the balance between consumption and generation at all times. The grid balancing services can be carried out in three categories according to time scales: primary frequency response (PFR), secondary frequency response and tertiary frequency response. Recently, due to the concern of decreasing inertia, a number of new frequency services are designed which are featured with fast responding requirement, namely fast frequency response (FFR). They are considered as one of the solutions to handle low system inertia and high ROCOF challenges. It is worth mentioning that FFR is used in this paper as a general term for frequency response services with fast responding requirement. It covers new services e.g. Enhanced Frequency Response (EFR) of UK, Fast Frequency Response of Ireland (FFR-IR), FFR of Australia (FFR-AUS) and Dynamic Regulation Signal (RegD) of PJM, although they differ in names and types.

\section{A. The Key Parameters in Frequency Response Services}

A typical droop-based frequency response setting is shown in Fig. 1, which essentially requires adaptive power with regard to frequency deviation. It is also a natural response from a conventional synchronous generator. Deadband, droop coefficient, response speed and duration time are the major parameters in frequency response services. A summary and comparison of those parameters in different regions are given in Table I and II for conventional PFR and emerging FFR services, respectively. In addition, the response time setting is shown in Fig. 2 and introduced in the following part.

\section{a. Deadband}

The deadband is an operating region centred around nominal frequency where the plant controller will not adjust its power in response to frequency deviations, as shown in Fig. 1. This deadband is a natural feature in conventional generators due to mechanical imperfections. Nowadays, the improvement in control accuracy and usage of power converters (especially for nonsynchronous generators) can largely reduce the deadband, while intentional deadband is still widely used to relieve system from continuous adjustment and to reduce wear\&tear.

From the grid point of view, a narrower deadband and a smaller droop gain can increase the contribution from generation units and improve the power grid frequency stability [12], [13]. However, on the other hand, they can cause undue wear\&tear of rotating machines and faster degradation of electro-chemical storage systems. Droop settings of 3-5\% and deadband no more than $\pm 17-36 \mathrm{mHz}$ are widely used as a good compromise, as shown in Table I [14]. The exceptions are:

- UK, Ireland and New Zealand use a narrower deadband due to their relative smaller system sizes and low inertia features;

- Ontario, Finland, Brazil, New Zealand and Singapore use a wider range for droop and/or deadband since in these regions the frequency response is procured by market and a wider range gives the generator more flexibility to adjust their participation.

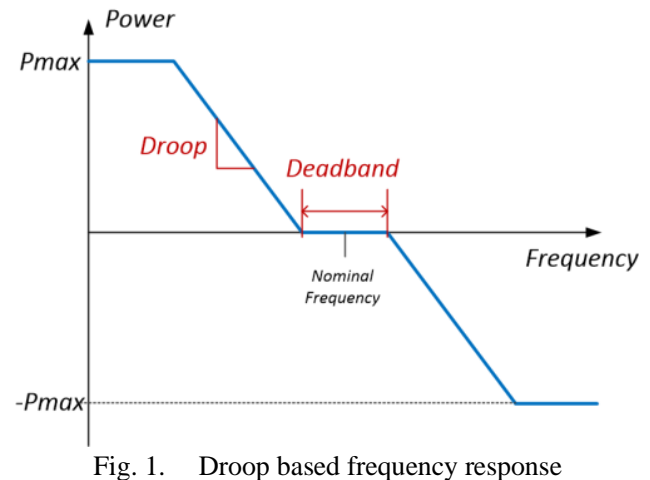

Fig. 1. Droop based frequency response

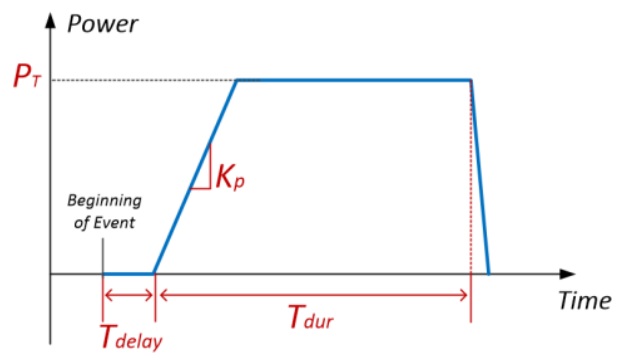

Fig. 2. Response time settings

\section{b. Droop Coefficient}

The droop coefficient characterizes the generator's power profile according to frequency deviations. It is defined by [14]:

$$
\operatorname{Droop}(\%)=100 \cdot\left(\frac{\Delta f_{\text {p.u. }}}{\Delta P_{p . u .}}\right)
$$


TABLE I COMPARISON OF INTERNATIONAL CASES - CONVENTIONAL SERVICES

\begin{tabular}{|c|c|c|c|c|c|c|}
\hline Region & Document & $\begin{array}{c}\text { Deadband } \\
( \pm m H z)\end{array}$ & Droop & $\begin{array}{c}\text { Response Time } \\
\text { Requirement }\end{array}$ & $\begin{array}{l}\text { Minimum } \\
\text { Duration }\end{array}$ & $\begin{array}{c}\text { Procurement } \\
\text { (Mandatory/Market) }\end{array}$ \\
\hline Global & IEEE 1547-2018 [77] & $\begin{array}{c}36 \\
(17-1000 \mathrm{mHz}) \\
\end{array}$ & $\begin{array}{c}5 \% \\
(3-5 \%) \\
\end{array}$ & $5 \mathrm{~s}(0.2-10 \mathrm{~s})$ & N/A & N/A \\
\hline $\begin{array}{l}\text { United } \\
\text { States }\end{array}$ & $\begin{array}{c}\text { FERC Order } 842 \\
\text { NERC BAL-003-1 [79] }\end{array}$ & $<=36$ & $<=5 \%$ & No undue delay & Sustained & Mandatory \\
\hline Texas, US & Nodal Operating Guides [87] & $\begin{array}{c}<=34 \text { (steam/hydro) } \\
<=17 \text { (all other) }\end{array}$ & $4-5 \%$ & $14-16$ & $30 \mathrm{sec}$ & Mandatory \\
\hline $\begin{array}{c}\text { New } \\
\text { England, } \\
\text { US }\end{array}$ & $\begin{array}{l}\text { Operating Procedure No.14 } \\
\text { [88] }\end{array}$ & $<=36$ & $4-5 \%$ & No undue delay & Sustained & Mandatory \\
\hline PJM, US & M-14D [90] & $<=36$ & $<=5 \%$ & No undue delay & Sustained & Mandatory \\
\hline $\begin{array}{l}\text { Ontario, } \\
\text { Canada }\end{array}$ & Market Rules IESO [89] & $<=36$ & $2-7 \%$ & $<1 \mathrm{~s}$ (activation time) & $10 \mathrm{sec}$ & Market \\
\hline Europe & ENTSO-E RfG (GIR) [11] & $0-500$ & $2-12 \%$ & $2-30 \mathrm{~s}$ & N/A & N/A \\
\hline UK & Grid Code [83] & $<=15$ & $3-5 \%$ & $10 \mathrm{~s}$ & $30 \mathrm{sec}$ & Market/Mandatory \\
\hline Ireland & The Grid Code [78] & $<=15$ & $3-5 \%$ & $2-10 s$ & $30 \mathrm{sec}$ & Mandatory \\
\hline Denmark & TR 3.3.1 for Battery Plants [84] & $<=10$ & $2-12 \%$ & $15 \mathrm{~s}$ & N/A & Market \\
\hline Finland & VJV2013 [91] & $0-100$ & $2-12 \%$ & $5 \mathrm{~s}$ for half $\& 30$ s for full & $2 \mathrm{~min}$ & Market \\
\hline Italy & TERNA Italian Grid Code [93] & 10 or 20 & $2-5 \%$ & $\begin{array}{c}15 \mathrm{~s} \text { for half } \& 30 \mathrm{~s} \text { for } \\
\text { full }\end{array}$ & $15 \mathrm{~min}$ & Mandatory \\
\hline Brazil & Procedimentos de Rede [92] & $<=40$ & $2-8 \%$ & $\begin{array}{c}9 \mathrm{~s} \text { reach } 90 \% \text { of full } \\
\text { response }\end{array}$ & $1 \mathrm{~min}$ & Market \\
\hline $\begin{array}{c}\text { New } \\
\text { Zealand }\end{array}$ & $\begin{array}{c}\text { Electricity Industry } \\
\text { Participation Code [94] }\end{array}$ & 0 (no deadband) & $0-7 \%$ & $6 \mathrm{~s}$ & $60 \mathrm{sec}$ & Market \\
\hline Singapore & Transmission Code [95] & 50 & $3-5 \%$ & $9 \mathrm{~s}$ & $10 \mathrm{~min}$ & Market \\
\hline \multirow{2}{*}{$\begin{array}{l}\text { South } \\
\text { Africa }\end{array}$} & The Network Code [96] & $<=150$ & $0-10 \%$ & $10 \mathrm{~s}$ & $10 \mathrm{~min}$ & Contracted \\
\hline & $\begin{array}{l}\text { Renewable Power Plant } \\
\text { Connection Code [97] }\end{array}$ & $\begin{array}{c}\text { Agreed with System } \\
\text { Operator }\end{array}$ & $0-10 \%$ & $10 \mathrm{~s}$ & $10 \mathrm{~min}$ & $\begin{array}{l}\text { Agree with System } \\
\text { Operator }\end{array}$ \\
\hline China & Q/GDW 696-2011 [86] & 200 & N/A & $\leq 0.2 \mathrm{~s}$ & $\geq 120 \mathrm{~s}$ & Mandatory \\
\hline
\end{tabular}

TABLE II COMPARISON OF INTERNATIONAL CASES - NEW SERVICES

\begin{tabular}{|c|c|c|c|c|c|c|c|}
\hline Region & Service & Type & $\begin{array}{c}\text { Deadband } \\
( \pm m H z)\end{array}$ & Droop & Power Requirement & $\begin{array}{l}\text { Response } \\
\text { Speed (s) }\end{array}$ & Duration \\
\hline \multirow{2}{*}{ Ireland } & FFR - Dynamic & \multirow{2}{*}{$\begin{array}{l}\text { Post-fault } \\
\text { contingency }\end{array}$} & $15-200$ & \multirow{2}{*}{ N/A } & $\begin{array}{l}\text { Min. power-step 1MW } \\
\text { Max. power-step 5MW }\end{array}$ & \multirow{2}{*}{2} & \multirow{2}{*}{$8-10 \mathrm{~s}$} \\
\hline & FFR - Static & & $200-700$ & & $\begin{array}{l}\text { Min. power-step 1MW } \\
\text { Max. power-step 75MW }\end{array}$ & & \\
\hline \multirow{2}{*}{ Australia } & FFR1 & $\begin{array}{l}\text { Post-fault } \\
\text { contingency }\end{array}$ & $50-150$ & \multirow{2}{*}{ N/A } & \multirow{2}{*}{ 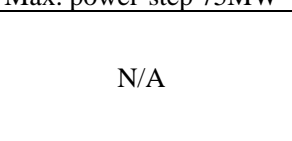 } & \multirow{2}{*}{$0.5-1$} & \multirow{2}{*}{$6 s$} \\
\hline & FFR2 & $\begin{array}{l}\text { Post-fault } \\
\text { emergency }\end{array}$ & N/A & & & & \\
\hline UK & EFR & $\begin{array}{l}\text { Pre-fault } \\
\text { continuous }\end{array}$ & $\begin{array}{l}15 \text { (high inertia) } \\
50 \text { (low inertia) }\end{array}$ & Envelope & $\begin{array}{l}\text { Min. power 1MW } \\
\text { Max. power 50MW }\end{array}$ & 1 & $15 \mathrm{~min}$ \\
\hline PJM, US & $\operatorname{Reg} D$ & $\begin{array}{l}\text { Frequency } \\
\text { recovering }\end{array}$ & N/A & N/A & Min. 0.1MW & 2 & Sustained \\
\hline
\end{tabular}

where $\Delta f_{\text {p.u. }}$ is the measured change of system frequency as a percentage with respect to nominal frequency, and $\Delta P_{p . u}$. is the corresponding active power change with respect to the generator's power rating.

The droop coefficient range is commonly designed by TSO. A consistent droop across all generators ensures that they contribute with respect to their capacities to the PFR. In a market environment, the droop coefficient can be adjusted (within a specified range) by the generator owner/operator based on the willing to provide more or less reserves to the service.

\section{c. Response Speed}

A fast responding service can effectively reduce the frequency deviation and ROCOF during contingency event, thus enhancing the usefulness of the service [13]. This feature is especially critical for the power grids with relatively smaller capacity and higher penetration of non-synchronous generators such as Ireland, UK and New Zealand. It can be clearly noticed that in Table I these three grids require shorter response time (full response delivery in 2 10s compare to 30s in Italy and Finland).

The response speed of a frequency response is majorly defined by the time delay $\left(T_{\text {delay }}\right)$ and ramp-up rate $\left(K_{p}\right)$, as shown in Fig.2. The time delay includes measurement time, communication delay and device activation time. The effect of these parameters on the usefulness of the service has been studied in [15]. It reveals that a high ramp-up rate is of great importance for the usefulness of the service, consequently power converter interfaced energy storage systems are highly suitable providers for FFR. In addition, it is also concluded that 
a time delay within 1s can be acceptable for ROCOF lower than $0.25 \mathrm{~Hz} / \mathrm{s}$ as long as the ramp up rate and total FFR capacity (shown as $P_{T}$ in Fig. 2) are sufficient.

Based on the above understanding, the grid inertia and the necessity of fast responding services are explained in detailed in the following part.

\section{B. The Necessity of FFR in a Low Inertia Grid}

System inertia is defined as the resistance to changes in the system frequency by storing/injecting kinetic energy from/to the system during power imbalance, which comes from the synchronously connected rotating machine.

The kinetic energy of a system $\left(E_{k}\right)$ is calculated as [16], [17]:

$$
E_{k}=\sum_{i=1}^{n}\left(\frac{1}{2} J_{i} \omega_{m i}^{2}\right)
$$

where $J$ and $\omega_{m i}$ are the moment of inertia $\left(\mathrm{kg} \cdot \mathrm{m}^{2}\right)$ and the angular speed of the rotor of the $i$-th rotating machine respectively, and $n$ is the total number of machines. The system total inertia constant is the ratio of total stored kinetic energy in $\mathrm{MJ}$, at synchronous speed to the MVA rating of the base system:

$$
H_{\text {sys }}=\frac{E_{k}}{S_{\text {base }}}=\frac{\omega_{\text {sm }}^{2}}{2 S_{\text {base }}} \sum_{i=1}^{n}\left(J_{i}\right)
$$

where $S_{\text {base }}$ is the MVA base of the system and $\omega_{s m}$ is the synchronous speed of the system ( $\mathrm{rad} / \mathrm{s})$. It can be seen that the total system inertia depends on the number of connected rotating machines as well as the kinetic energy stored in their rotating mass. In comparison, the instantaneous physical storage of a power converter (no matter what is connected at the source side) is the energy stored in its DC-side capacitor, which is negligible compared to the rotational inertia of synchronous machines.

The initial ROCOF that is determined by the size of the power imbalance and the system inertia can be expressed as:

$$
\text { ROCOF }=\frac{f_{0}}{2 H_{\text {sys }}} \frac{\Delta P}{S_{\text {base }}}=\frac{f_{0} \Delta P}{2 E_{k}}
$$

where $\triangle P$ is the disturbance size and $f_{0}$ is the nominal system frequency. Obviously, the initial ROCOF is larger if the power disturbance is bigger or the system stored energy is smaller. As more conventional generators are substituted by converter interfaced generations, the $H_{s y s}$ and $E_{k}$ become smaller. Moreover, the increasing power consumption and the stochastic feature of renewable generation cause more frequent and higher power disturbances. The combination of the two factors can result in larger ROCOF and thus worse the grid stability.

Conventionally, the frequency deviation caused by power variation and contingency events is compensated by PFR majorly from rotational generators. However, their inherent deadband and slow response usually result in a full response power delivery in around 10-20s which is too slow for a low inertia system. With the help of a fast responding energy source, such as a converter interfaced ESS, power can be delivered to effectively mitigate the frequency nadir and ROCOF [15]. An example is given in Fig. 3, which simulates a frequency loss event for a big generator in a low inertia network and compares the frequency behavior with and without an FFR. It can be seen the frequency nadir is significantly reduced as well as the
ROCOF.

Thus, solutions such as converter interfaced ESSs can be beneficial to the grid stability, safety and reliability, by providing FFR type services. A number of energy storage technologies are listed in Table III that are potential candidates for providing such services, thanks to their considerable power/energy size and fast response time [5], [18].

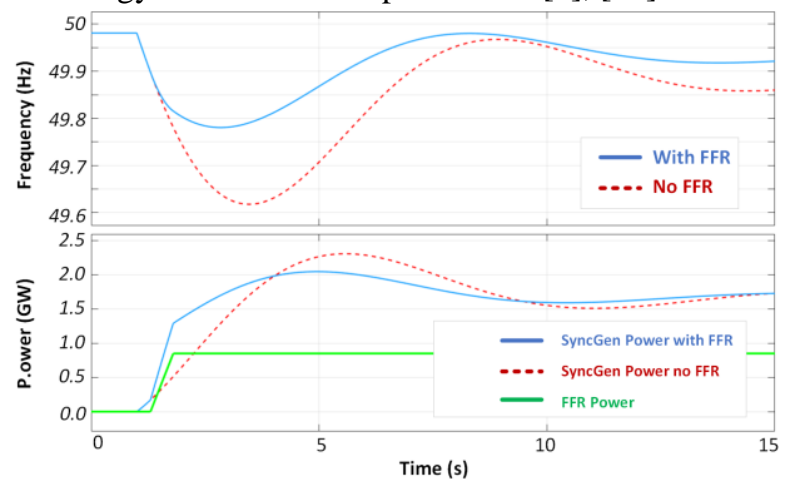

Fig. 3 Comparison of frequency performance with /without FFR service.

TABLE III. EXAMPLES OF ES TECH SUITABLE FOR FAST RESPONSE SERVICES

\begin{tabular}{c|c|c|c|c}
\hline Technology & $\begin{array}{c}\text { Power } \\
\text { Range } \\
\text { (MW) }\end{array}$ & $\begin{array}{c}\text { Energy } \\
\text { Ratings } \\
\text { (MWh) }\end{array}$ & $\begin{array}{c}\text { Response } \\
\text { Time }\end{array}$ & $\begin{array}{c}\text { Discharge } \\
\text { Time }\end{array}$ \\
\hline $\begin{array}{c}\text { Flywheel } \\
\text { (converter) }\end{array}$ & $0.1-400$ & Up to 5 & $<=4 \mathrm{~ms}$ & Up to $15 \mathrm{~min}$ \\
\hline $\begin{array}{c}\text { Lithium } \\
\text { Batteries }\end{array}$ & $\begin{array}{c}\text { up to } 50 \text { or } \\
\text { more }\end{array}$ & Up to 20 & Few to $40 \mathrm{~ms}$ & $\begin{array}{c}\text { minutes to } \\
\text { hours }\end{array}$ \\
\hline Flow Batteries & $\begin{array}{c}\sim 3,50 \\
\text { possible }\end{array}$ & Up to 60 & Few to $40 \mathrm{~ms}$ & $\begin{array}{c}\text { seconds to } \\
\text { hours }\end{array}$ \\
\hline $\begin{array}{c}\text { Advanced } \\
\text { Lead-Acid } \\
\text { Batteries }\end{array}$ & up to 40 & Up to 40 & Few to $40 \mathrm{~ms}$ & $\begin{array}{c}\text { seconds to } \\
\text { hours }\end{array}$ \\
\hline $\begin{array}{c}\text { Super- } \\
\text { capacitors } \\
\text { (high voltage) }\end{array}$ & up to 50 & Up to 0.28 & $10-20 \mathrm{~ms}$ & $\begin{array}{c}\text { milliseconds to } \\
1 \text { hour }\end{array}$ \\
\hline
\end{tabular}

\section{CHARACTERISTICS OF FFR SERVICES IN SELECTED AREAS}

The typical examples of FFR services that are pondered here: RegD signal from PJM (US) [19], EFR from National Grid (UK) [20] and FFR-IR from EirGrid (IRE) [21]. The design of these services also considers the feasibility and cost for ESSs, such as energy neutral design from PJM, US [19] and envelope design from National Grid, UK [20]. This section performs a review on these selected services.

\section{A. Enhanced Frequency Response, National Grid, UK}

National Grid, UK has recently procured resources (ESS) for a new PFR service, namely EFR [20]. EFR differs from conventional PFR in its fast response speed. The characteristic of EFR are summarized as follows:

- Service delay includes the time to detect a frequency deviation plus the time for response instructing and the time for ESS to deliver output change. The total delay has to be no greater than $1 \mathrm{~s}$, with the time delay for detection and instructing response no greater than $500 \mathrm{~ms}$.

- The service delivery envelops (wide and narrow band services) are shown in Fig. 4. The ESS output must always be within the upper and lower envelopes.

- The deadband is defined as the frequency range between 
reference point $\mathrm{C}$ and $\mathrm{D}$ where the ESS gives zero MW output. This area can be used by the ESS to manage its state-of-charge for later services.

- The power limit and droop coefficient can be calculated by the reference points given in two tables in Fig. 4.

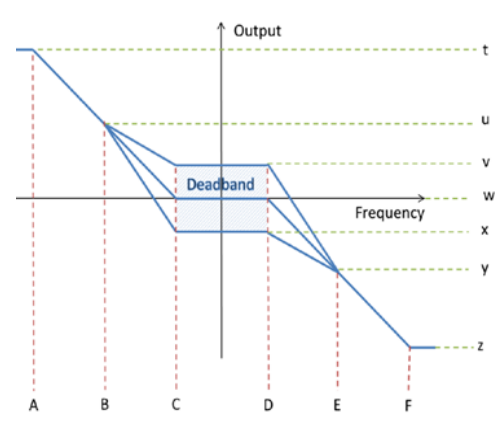

Fig. 4 Enhance frequency response envelope [18].

- The capacity of high and low response is symmetrical.

- ESS connection should meet grid code minimum requirements which also give guidelines on voltage and reactive power control.

- During EFR provision, it is not allowed to provide any other services that could impair the EFR service quality. But it is allowed to participate in the provision of other services outside the EFR service period.

In addition, the design principles are also briefly summarized here:

- Frequencies outside $50 \pm 0.25 \mathrm{~Hz}$ are considered post-fault, and the service provider must follow the exact profile defined in Fig. 4; frequencies that are within $50 \pm 0.25 \mathrm{~Hz}$ are considered pre-fault, for which an envelope is designed so that the service provider can have room to manage its operating condition.

- According to [22], the maximum delivery is specified to be $50 \pm 0.5 \mathrm{~Hz}$, which set a $0.5 \mathrm{~Hz}$ frequency deviation limit. Increasing the figure will make the service less useful while lowering the figure will ask service providers to contribute more energy (enhance the cost and make the service hard to deliver).

- The output power of the provider can vary within $\pm 9 \%$ of capacity allowing some flexibility and lowering the cost. However, increase this figure will limit the service provision capability.

- Frequency insensitivity band has two settings: $50 \pm 0.05 \mathrm{~Hz}$ and $50 \pm 0.015 \mathrm{~Hz}$. When grid inertia is high, the $\pm 0.015 \mathrm{~Hz}$ band is used. ESSs use this deadband in high inertia conditions so that they can provide useful services when the frequency is relatively stable. $\pm 0.05 \mathrm{~Hz}$ is used when the grid is in low inertia and frequency is less stable experiencing high rate of change.

- The ESS must be able to deliver at $100 \%$ its EFR capacity for $15 \mathrm{~min}$ minimum. Lowering this figure, the service delivery time may not be sufficient to allow the various reserve services to react; on the other hand, increasing this time is not necessary and will result in higher cost.

\section{B. Fast Frequency Response, EirGrid/SONI, Ireland}

EirGrid/SONI, Ireland is developing a multi-year programDelivering a Secure, Sustainable Electricity System (DS3) [4] [21], which defines two additional fast frequency services: FFR and SIR. These services aim to enforce grid security and stability.

SIR is the active power output and synchronizing torque that a unit can provide following disturbances. Synchronous machines based generators, condensers and loads are naturally available for providing this service, and ESSs, with proper measurement and control, can also be a significant player. An example SIR is shown in Fig. 5 (a).

FFR is defined as the additional increase in MW output from a generator or reduction in demand following a frequency event that is available within 2 seconds of the start of the event and is sustained for at least 8 seconds. The extra energy provided in 2 to 10 second timeframe by the increase in MW output must be greater than the any loss of energy in the 10 to 20 second timeframe due to a reduction in MW output below the initial MW output (i.e. the hatched blue area must be greater than the hatched green area in Fig.5 (b)).

\section{RegD Signal, PJM, US}

PJM defines two types of frequency regulation services: RegA and RegD. RegA refers to traditional generators which have limited ramp rates; RegD is designed for fast ramping resources, such as batteries.

The control scheme of RegD is shown in Fig. 6. The filtered area control error (ACE) is first sent to a PID controller to generate an ACE correction signal (ACS) as a regulation reference. The ACS is then separated into two signals by a lowpass filter and a high-pass filter respectively. The high-pass filtered signal, is filtered again by a low-pass filter to remove noise and RegD regulation signal is generated accordingly. The low-pass filtered signal is the RegA regulation signal.

In addition, a new Conditional Neutrality Controller is designed and implemented since 2017, as the feedback loop shown in Fig. 6 [19]. RegA signal for ramp-limited resources, is also used to balance energy to zero neutral when available to do so in order to manage the State-of-Charge (SoC) of RegD service providers.

In the feedback loop, the cumulative sum of the RegD signal, namely the total absorbed or generated energy by RegD resources, is calculated, and a simulated SoC (the percentage of used energy in total RegD capacity) is generated and used to determine the payback gain. Three payback gains can be set according to the simulated SoC:

1. Simulated SoC between $-25 \% \sim 25 \%$, the payback gain is set to a value to reset the SoC of RegD resources back to neutral within $15 \mathrm{~min}$;

2. Similarly, for SoC between $25 \% \sim 50 \%$ or $-50 \% \sim-25 \%$, this has to be done within $7 \mathrm{~min}$;

3. For SoC between $50 \% \sim 100 \%$ or $-100 \% \sim-50 \%$, it is $3 \mathrm{~min}$.

The selected payback gain is then added into the total regulation reference to adjust the output of the RegA resources. The more the RegD resources are charged or discharged, the 


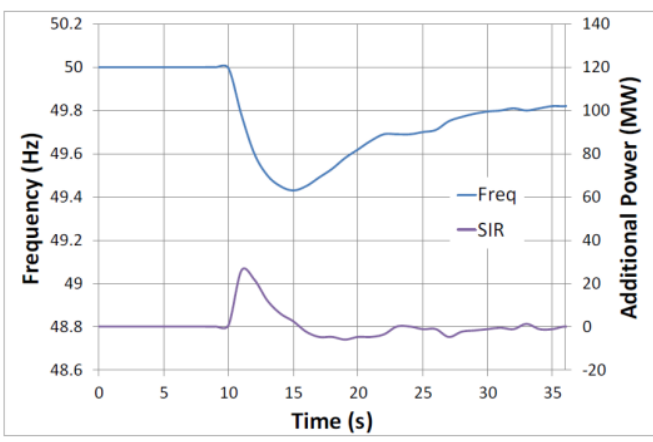

(a)

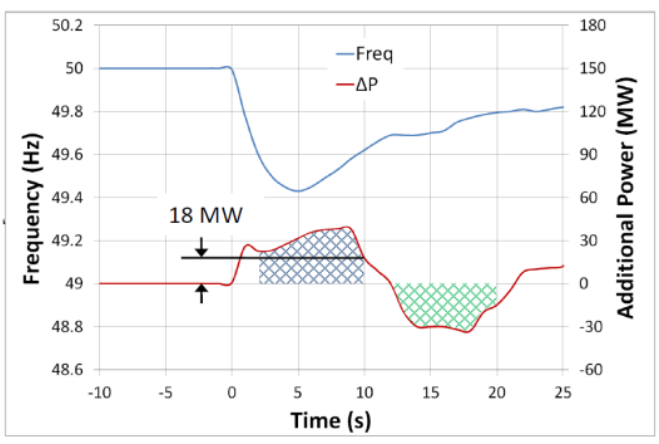

(b)

Fig. 5 DS3 new services: (a) Synchronous Inertia Response; (b) Fast Frequency Response.

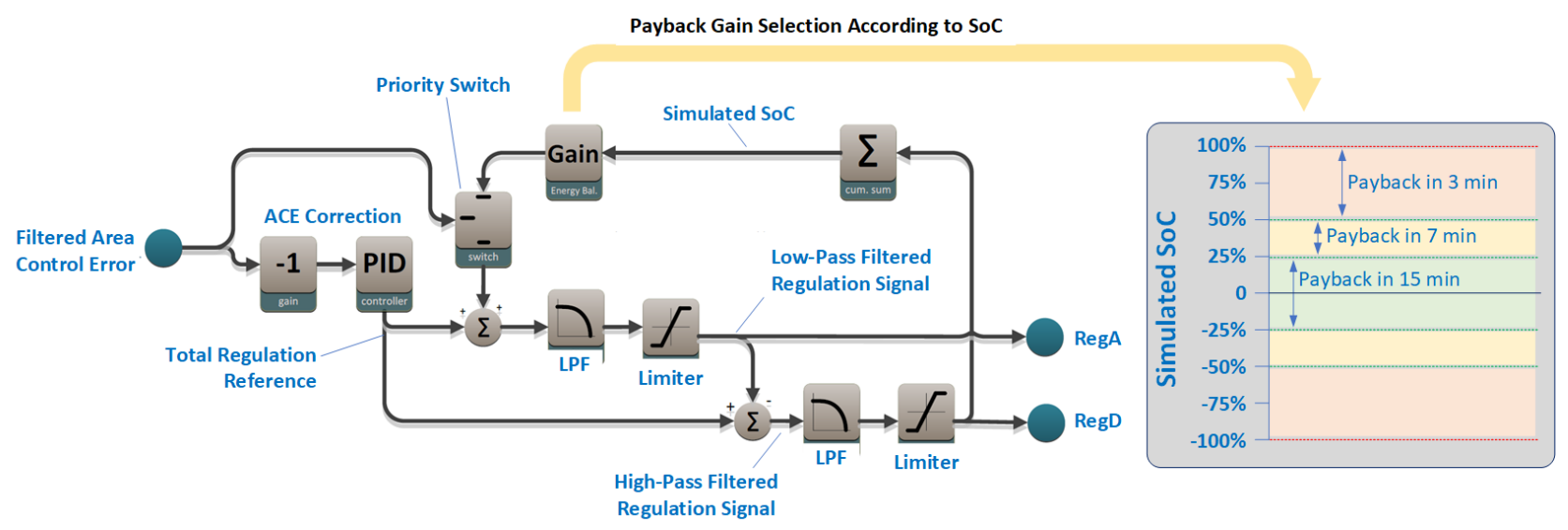

Fig. 6 Conditional Neutral Controller, PJM.

more efforts the RegA resources will make to bring them back to neutral.

Furthermore, a priority switch is also used in case that if the ACE is very large, the controller places extra priority on ACE control by switching the payback loop off and using the ACE signal instead.

\section{Considerations for ESS}

For ESSs, it is commonly recognized that they can face more challenges if they asked to follow the same requirements as other generators. As a result, special settings have been applied in the emerging services mentioned above to ease the ESS integration. For example, the FERC order 842 [23] has stated that in order to alleviate the potential of over-charge/discharge and excessive wear\&tear, a SoC (state-of-charge) range shall be identified before the connection to provide timely and sustained PFR. Furthermore, it is also widely agreed that the ESS can have more contribution to the grid stability if featured services or requirements are pre-designed, resulting in the emerging services as FFR-IR and EFR in order to take advantage of the accurate and fast response of converter interfaced ESS.

Notably, EFR is as a continuous control service which is provided via a droop response to frequency. The aim of the service is to manage pre-fault system frequency (ie. to maintain system frequency closer to $50 \mathrm{~Hz}$ under normal operation), but not designed to arrest frequency decline post-fault [24], [25]. This makes it fundamentally different to the FFR services specified in EirGrid, Ireland and NEM, Australia, which are targeted at post fault controls (ie. managing a big drop in frequency, or a big spike in frequency) [24]. Thus, the FFR in EirGrid and NEM do not use a droop control, they are static frequency response triggered at a certain frequency level. The EFR service is more similar to the PJM fast regulation service model, although in the PJM case a central signal (AGC) instructs the battery on what to do (rather than requiring a response based upon locally measured frequency, as is the case for EFR in Great Britain) [24], [25].

\section{CRITICAL REVIEW OF TECHNICAL INVESTIGATIONS}

This section gives a high-level review on the technical investigations for ESS applications in FFR service. For real world applications there is still lack of understanding on several essential issues, e.g.:

- Which is the better storage solution for FFR in terms of cost and performance?

- How much total FFR capacity is needed to maintain the grid stability?

- How to optimally position the FFR resources?

- Which is the better way of controlling and coordinating FFR resources?

- What are the challenges of using ESS for multiple grid services?

Hence, this section is divided into three parts: i) ESS planning which includes cost evaluation, sizing and placement methods; ii) ESS control, and (iii) challenges of multi-service provision.

\section{A. ESS Planning}

\section{- Cost Evaluation for FFR}


The high cost of storage systems has been a major obstacle for wider application in power grids, although their benefits are obvious. It is of great importance to select the cost-efficient solution for a certain application. For FFR use purpose, it can be seen from Table II that, the FFR-IR and FFR-AUS are power critical services which require high power capability within short duration time (6 10s). On the other hand, the EFR and RegD are energy critical services asking for a service duration of $15 \mathrm{~min}$ or more.

The studies in [26] and [27] have tried to evaluate the cost and suitability of storage solutions in different applications. The two studies have common recognition that flywheel is the most cost-effective solution for high power and short duration primary frequency service due to the low power capital cost, long lifetime and mature technology. Super-capacitor is comparable with flywheel for FFR purpose although lifetime is the major limiting factor. In addition, it is worth noting that the no-load power loss is also an importance factor since the typical FFR services are designed for contingency event which has low occurrence rate. No-load losses are omitted in both studies [26] and [27], and super-capacitor typically has much lower no-load losses compared to flywheel. For EFR and RegD, as they also require considerable amount of energy, $\mathrm{Li}$-ion batteries are naturally preferred from cost and efficiency point of view [28].

In summary, in order to have a complete evaluation and comparison of potential solutions, it is necessary to take into consideration the following aspects:

- Capital cost of major system components, i.e. storage systems, converter, control systems, mechanical systems, cooling and environmental control, etc.

- Footprint of the solution, indoor, outdoor and special construction requirements, etc

- Operational and maintenance costs

- Power losses and equivalent cost

- Use mode and technical specification

- Sizing of FFR

Sizing of ESS is one of the key issues to achieve the technoeconomic sustainability of ESS for grid services. It is to be noted that compare to inertia response services, the FFR/PFR service requires much higher energy ratings. Though this field is promising and relatively new in operation, very few researches have been done on the development of method for estimating/optimizing the size of ESS for IR and FFR services.

A critically brief review is done here as well, to understand the progress of the ESS sizing for these services. In most of the cases, sizing of ESS is done arbitrarily [29], or a number of simulation for various ESS sizes is executed and the optimal size is chosen according to desired results [30]. A probabilistic approach with high number of simulations is also applied when the power network is highly penetrated from renewable energy such as solar [31]. The impact of sizing upon the overall frequency dynamics is further extended in [32] where a method for estimating the ESS sizing is presented targeting the power/frequency characteristics of the required services.

Sizing of ESS was optimized in few cases and mostly done to maximize the financial benefits from the grid ancillary service market [33], [34] or in microgrid application [35]. When it comes to the techno-economic benefits, very few are found. In [36], a co-optimization approach is investigated to solve the storage investment problem such as finding the type, placement and sizing of ESS in a transmission-constrained network. Regarding the ESS planning, in [37], authors prove that the minimum operating cost is a decreasing convex function of the ESS energy capacity. This leads to the optimal sizing of ESS that strikes a balance between the capital investment and operating cost.

\section{- Placement of FFR}

The state-of-the-art review reveals different applications of energy storage such as virtual inertia response and inter-area oscillation damping provision [38]-[40], optimal power flow [41], placement in the network and control tuning. It is recognized that apart from the total inertia response (IR) required in the system, its placement is also very important. Both small-signal system linearization based [38], [39] and non-linear system, simulation based [40] techniques have been used in the process of location optimization. The computation effort required to achieve the result of the optimisation exercise is also addressed in [38], [39]. The constraints, within which the optimisation is carried out, includes the characteristics associated with the battery such as its power limit and SOC, and the line limits of the power system which also impacts the placement [38]-[41]. Finally, it is suggested that in order to maximise the value from the multiple service provision capability of energy storage devices, tools are required that take into account the different application time horizons from seconds to minutes for simulation durations of a year, which will inform the overall best location for the energy storage device [42].

\section{B. ESS Control}

The operation of the ESSs participating in frequency response services has to follow the technical specifications given by respective grid standards. In general, the control methods for fast responding frequency services can be categorized into four types: $P$ - $f$ (active power-frequency) droop, triggered static response, AGC signal, and emulated inertia control:

\section{- $P$ - $f$ Droop Control}

$P$ - $f$ droop control (or dynamic frequency response as defined in National Grid, UK) is used in most conventional and emerging frequency response services as can be seen in Table I and II [13], [43]-[45]. The active power output of the generator is in proportion to the frequency deviation. It is an inherent feature of conventional synchronous generators guaranteeing automatic frequency recovering and power sharing. Nowadays $P-f$ droop characteristic (with a deadband) is also applied to converter interfaced energy resources as a requirement for grid interconnection.

\section{- Static Frequency Response}

National Grid, UK and EirGrid/SONI, Ireland also define static frequency response services (see Table I and Table II), which are triggered at a certain frequency level instead of using a proportional droop [21], [24], [43], [46]. A constant power or discrete step of power is generated according to the frequency 
level. Although the large majority of frequency response requirements in UK are met by dynamic providers, static providers can also be of use especially during a large loss of generation. The static service is provided by fast acting resources or demand side cut-off.

On one hand, the fast and full power response given by static providers can be more effective to save the post-fault frequency drop from too high rate-of-change and too low nadir. In addition, as demonstrated in the Smarter Network Storage (SNS) project, the higher aggregated active power contribution by static response can potentially gain higher income compared to the $P$ $f$ droop based dynamic services [47]. On the other hand, it has also been concluded that the static response service is less beneficial to the pre-fault frequency stabilization compared with the continuous dynamic response service. It is more suitable for contingency frequency response, such as the FFR services in Ireland and Australia.

\section{- Automatic Generation Control}

PJM, US uses a centralized automatic generation control signal to perform frequency regulation [19]. Although this frequency service is indeed a secondary frequency regulation which is not comparable with the primary frequency response, the authors decide to involve it since a dynamic regulation (RegD) is designed which also eases the service provision from energy storage systems and it is also a fast responding service which can take full advantage of ESS [19]. The RegD signal is generated according to the area control error and sent to service providers. The regulation speed of RegD is comparable with the emerging FFR and EFR services and provides more accurate regulation of the frequency level. The conditional neutral control design also provides proper coordination of the service providers. However, the communication delay, communication failure and cyber-attack can jeopardize the safety of the utility grid.

\section{- Inertia Emulation Control}

This type of control regulates the interfacing converter to emulate the mechanical inertia, e.g. mimic the behavior of a synchronous machine. The main objectives are to provide virtual inertia, integrate droop control, enable smooth islanding transition, and provide voltage support. It can be applied in converter interfaced energy resources, e.g. wind turbine, PV and ESS [48]-[54]. The active power output is in proportion to the rate-of-change-of-frequency by, in most cases, implementing a swing equation, thus can effectively mitigate ROCOF. The following part gives a brief review of typical inertial emulation control methods.

$P-d f / d t$ based droop control [49], [52] regulates the power in proportion to the ROCOF so as to provide virtual inertia to the system. However, this type of control cannot avoid PLL in the control loop thus can be unstable in case of grid fault or weak grid conditions.

VIrtual Synchronous MAchine (VISMA) control [55] integrates a high order synchronous machine model in converter control scheme and generates current reference for the cascaded current controller. It is a natural and straightforward implementation of machine model. However, the complexity due to the high order model and the lack of voltage stiff feature are the major challenges of applying this method.

Synchronverter control [56] implements a swing equation based inertia emulation control and a reactive power-voltage droop to generate the angle and voltage amplitude references respectively. These two references are fed into modulation directly without inner voltage or current control loops. However, the major risk is the difficulty of integrating voltage and current saturation due to absence of inner voltage and current loops.

Power synchronization control (PSC) [57] combines the swing equation based inertia emulation control with vector current control and realizes stable operation in weak grid condition by supporting both inertia and stiff voltage feature. The current limitation is also guaranteed by the current control loop.

In summary, inertia emulation controls show promising performance for low inertia power grids especially during the transient of frequency disturbances. The major challenges are still the emulation of a stiff voltage source feature and the proper integration of current limitation during transient.

\section{Challenges for Multi-Service Provision from ESS}

The maximized utilization of ESS by providing multiple services could improve the business cases of grid-scale ESS, and encourage more investment and applications [47]. Thus, some of the ESS operational scheduling problems considering multiple services are formulated in [58], [59]. However, the challenges exist in several aspects:

\section{- Complicated control}

The concurrent and multiple service provision requires the ESS converter to be able to operate in different modes e.g. automatic voltage control mode for voltage support, automatic frequency response mode for frequency service. Such services should be coupled to match the best energy and power ratings of the batteries. At this stage, good coordinated control is very important as it requires the battery to make charging and discharging decisions at different time scales while accounting for the stochastic information such as load demand, electricity prices, and regulation signals. Discussion on different control strategies has been left to analyze in another research paper.

Analytical approach shows that solving the problem for even a single-day operation would increase the computational complexity due to the large state space and the number of time steps. In that case, dynamic programming approach could reduce this complexity [60]. The other problem is the multiple service provision has huge impact on the storage life time degradation [61]. Part of these issues can be overcome by introducing hybrid ESS. Integration of electrochemical batteries and super-capacitor with a coordination of current and voltage control loop in the converter could be a good solution for this, which has been validated in $50 \mathrm{~kW}$ test-bench [60]. Implementing ESS for multiple service provision in transmission and High Voltage DC (HVDC) networks could also be achieved by introducing HVDC-scale modular multilevel converter (MMC) [60]. In general, the combination of such issues largely complicates the control, operation of ESS, increases the development cost considerably and hence require 
extensive research and grid-scale demonstration as well.

\section{- Coordination with existing grid facilities}

The existing grid facilities, such as On-Load Tap Changers (OLTC), distributed generators (DG) with grid forming converters, synchronous condensers, and so on, may have unexpected interactions with ESS operating in different modes. The concurrent service provision certainly puts more load on the grid side asking for enhanced operation strategies. In such case, harmonious integration of fast acting ESS with coordinated control of SoC and a proposed unified frequency controller [62], and co-located ESS and DGs with local voltage controller [63] could maximize the active power production during the high penetration of DGs when voltage limits are violated.

\section{GRID-SCALE ENERgy Storage System ProJects}

This section introduces three real-world projects: 1) example from UK shows the effectiveness of Li-ion (the most popular and matured ESS technology) for frequency response service; 2) the hybrid (Flywheel and Pb-acid battery) solution in Ireland demonstrates the possible responses for FFR; 3) PJM demonstrated the value of another hybrid (Ultra-capacitor and $\mathrm{Pb}$-acid battery) solution UltraBattery ${ }^{\circledR}$ for RegD service along with some demand side management strategy.

\section{A. Smarter Network Storage, UK}

In 2012, UKPN designed the SNS project to explore the technical and commercial feasibility as well as regulatory barriers to multiple applications of large-scale battery storage system [47]. The storage site was commissioned in December 2014, comprising a 6MW, 7.5MVA, 10MWh Li-ion battery. Its primary applications were peak shaving, frequency response, electricity reserve and tolling. Concurrent provision of frequency response and reactive power support were also tested.

Firm frequency response is one of the main tests in this project including both dynamic and static frequency response. Firm frequency response requires: i) delivery of full service within 10s; delivery of service continuously for $30 \mathrm{~min}$; service type can be dynamic or static. Dynamic firm frequency response (DFFR) demands active power output from ESS following a droop curve with a $0.05 \mathrm{~Hz}$ deadband $(50 \mathrm{mHz}$ for wide band, $15 \mathrm{mHz}$ for narrow band) and a $\pm 0.3 \mathrm{~Hz}$ frequency sensitive mode range. Static firm frequency response (SFFR) contracts ESS with a fixed output power level and activates the service when frequency exceeds the upper or lower boundary [47]. Besides, the multi-service provision capability of ESS was also tested [47], in which active and reactive power can be delivered concurrently. Both above applications have demonstrated the effectiveness of SNS in delivering required services. Reactive power support service from ESS may reduce distribution network losses by optimizing the reactive power flow, while the power capacity of the connecting converter (reactive power capability) decides the impact level of such service provision. Voltage control service, majorly managed by controlling reactive power in inductive grids, can improve voltage stability and reduce the stress of substation's OLTC thereby improving life span.

In addition, it has also been indicated in the project report that the concurrent service provision feature can potentially maximize the utilization and business value, however, the combination of services, if not well coordinated, may cause voltage step magnitude exceedance. Further study has to be carried out in this regard.

\section{B. Flywheel-Battery Hybrid Grid Storage, Ireland}

Under the background of DS3 as well as the renewable penetration target, a number of new grid scale energy storage systems have been trialed in Ireland. The example illustrated in this section is a $480 \mathrm{kVA}$ rated flywheel/battery hybrid energy storage solution developed by Schwungrad Energie Limited. A demonstration project was carried out to show how the hybrid solution responded to real frequency events over a period of 9 months. The goal was to provide system services (without participating in the market) up to $20 \mathrm{~min}$ with full power achieved in the timeframe of $500 \mathrm{~ms}$ (measured from the time of system frequency falling through $49.80 \mathrm{~Hz}$ ). The metrics used to classify the quality of performance were the response time and sustainability of power output. For a commercial installation the target would be to deliver the following DS3 products: FFR, SIR, as well as primary, secondary and tertiary operating reserves [4].

Four different control modes were tested as shown in Fig. 7. The deadband of the frequency response is assumed $50 \mathrm{mHz}$, within which range the storage can manipulate its $\mathrm{SoC}$ freely. Frequency response is triggered at the threshold of $49.8 \mathrm{~Hz}$ requiring that the storage systems reach their full power output within $500 \mathrm{~ms}$ and sustained for $5 \mathrm{~s}$. The performance of the four control methods is compared:

1) Static response by ROCOF predicted triggering (Mode I). In this control mode, when the ROCOF exceeds the threshold a frequency event is predicted. As a result, the control system generates a "full blast" command before the frequency reaches the frequency threshold value of $49.8 \mathrm{~Hz}$. It can be seen that both the battery and the flywheel reach their full response power before the frequency reaches $49.8 \mathrm{~Hz}$ and sustained for 5s. The advantage of this control mode is that due to the prediction of the event, the response is delivered ultra-fast. However, the issues related with this control mode include: i) accuracy of prediction is questionable, may cause false response, ii) arrested of response before the frequency returning back into deadband can reduce the usefulness of the service. In addition, the hybrid system use-mode is not optimized. The ideal use of hybrid battery with flywheel is to use flywheel as a fast and high power responding device and use battery as a low power and sustained responding resource to maximize the frequency support.

2) Static feedback response by ROCOF predicted triggering (Mode II). Similar to Mode I, the frequency event is 

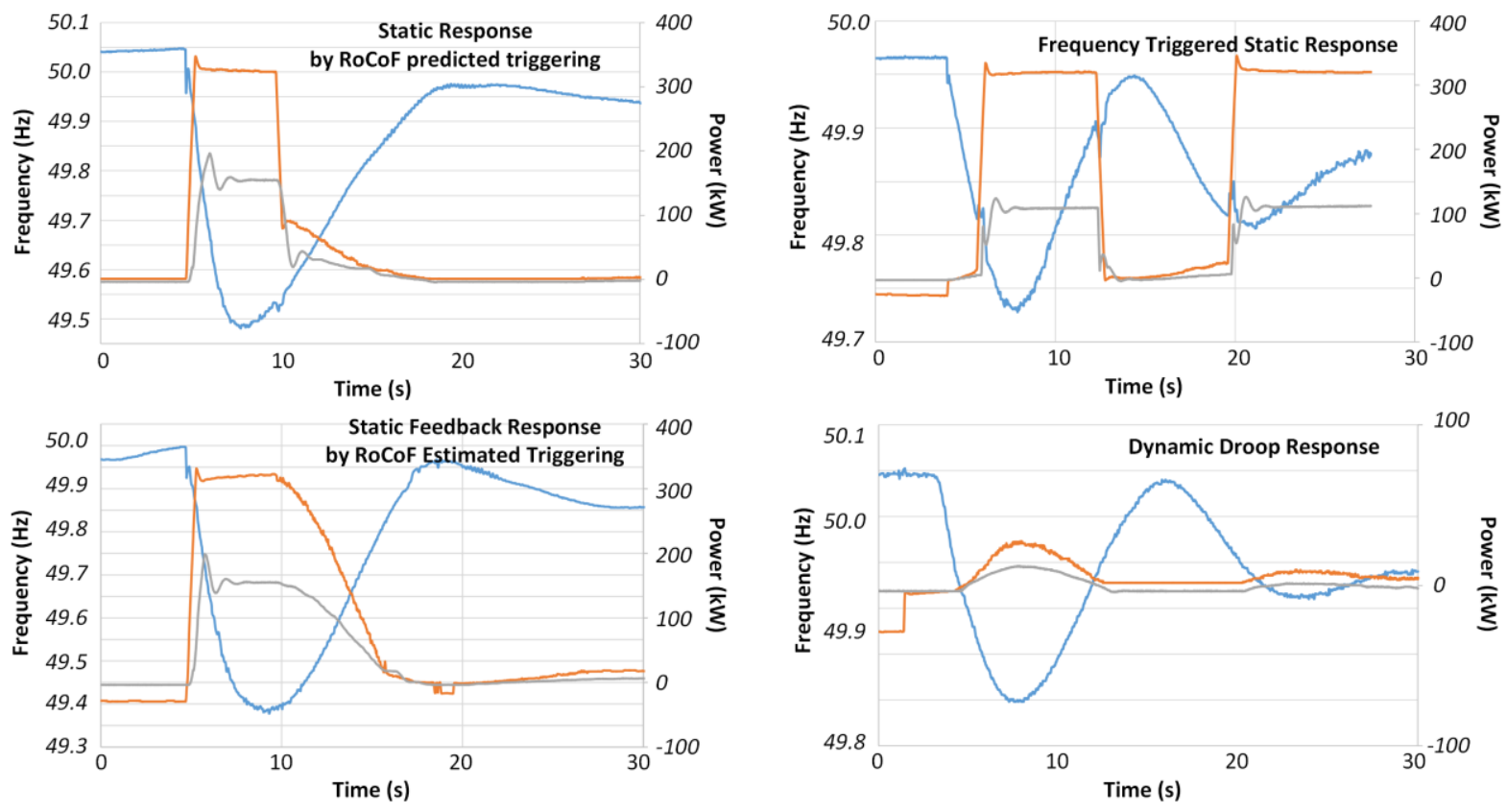

Fig. 7 Flywheel-Battery Hybrid Grid Storage performance in FFR.

predicted by ROCOF measurement and the frequency response is triggered before reaching the threshold. The service is sustained for $5 \mathrm{~s}$, and different from Mode I, the storage systems gradually reduces its power based on a droop gain instead of a sudden arrest of service. The advantage of this mode is the smooth reduction of power according to frequency condition which can potentially benefit the grid stability. However, the accuracy of the prediction is still uncertain and more energy needs to be delivered in order to have the smooth reduction of power.

3) Frequency triggered static response (Mode III). In this mode, the initial ROCOF of the event is not high enough to predict the event, accordingly the frequency response is triggered near the threshold of $49.8 \mathrm{~Hz}$. Both flywheel and battery reach their full response after the triggering event. The response time is recorded as within 500ms according to the report. The response is sustained until the frequency reach $49.9 \mathrm{~Hz}$. The event is triggered again at around 20s. Compared with Mode I and Mode II, the time to reach full response after the threshold is longer but still within the $500 \mathrm{~ms}$ requirement. In addition, taking a solid threshold as the triggering event can be considered more reliable.

4) Dynamic droop response (Mode IV). The dynamic droop mode emulates the behavior of a conventional generator which continuously deliver power according to frequency deviation. In summary, the trial results have demonstrated the capability of battery and flywheel storage systems to deliver fast frequency response service. Several control modes have been tested which provide very fine reference for future implementation of such devices. The operation of a hybrid energy storage system is also validated showing satisfying results. Nevertheless, a number of key issues are still unclear, including:

1) The best use-mode of a hybrid energy storage system is not explored. A better coordination between battery and flywheel can be achieved to maximize the grid support, reduce operational cost, and improve owner profit.

2) ROCOF prediction based triggering method needs to be further evaluated before real world application, since the frequency behavior is becoming more dynamic.

3) $500 \mathrm{~ms}$ response time is much shorter than the FFR requirement of $2 \mathrm{~s}$, and in the case of Mode I and Mode II the response time is even shorter. False triggering could incur.

4) The four control modes can be compared from the usefulness and economy point of view.

\section{East Penn Smart Grid Demonstration Project, US}

This smart grid project of PJM demonstrates distributed energy storage for grid support, in particular the economic and technical viability of a grid-scale, advanced energy storage system using UltraBattery® technology with a total regulation capability of $3 \mathrm{MW}$ for frequency regulation ancillary services and demand management services [64]. This demonstration system follows PJM's RegD signal. Over the course of the demonstration, the system has been operating at various power levels and durations (typically 2 2.4MW for maximum one hour duration).

The testing results are shown in Fig. 8 [64]. The response time of the system to a $3 \mathrm{MW}$ command was determined to be less than 4 seconds, or $0.75 \mathrm{MW} / \mathrm{s}$. The perfect following of the regulation signal and fast response result in high performance score and increased payment compensation. The averaged signal following accuracy is $94.2 \%$ during the operating time. The SoC is maintained within $45 \sim 55 \%$ validating the energy neutral control of RegD as was introduced in Section IV.C.

In addition, a comparison is also given in Fig. 9 showing the accuracy difference between different technologies in participating PJM regulation service [65]. The results clearly indicate the advantage of using battery as ESS can provide more efficient and useful service to the grid. 


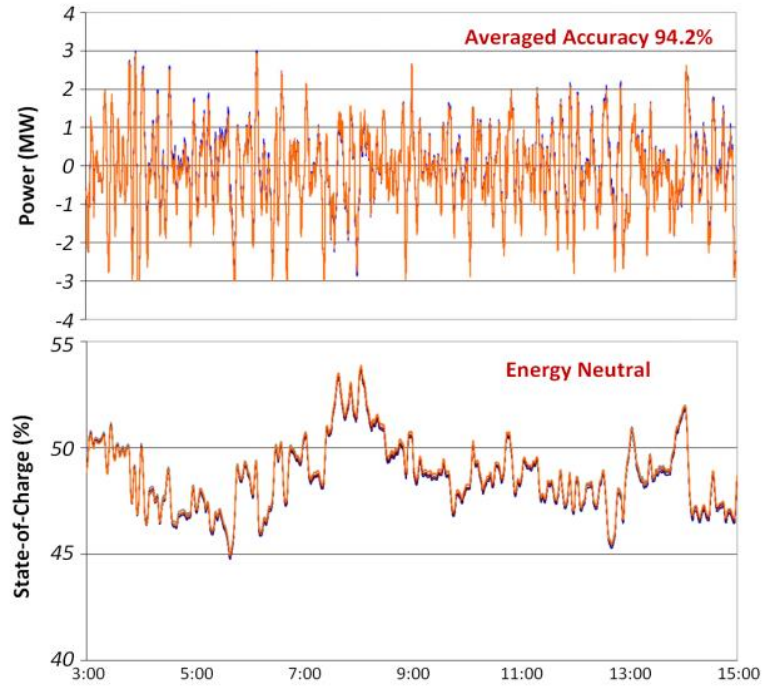

Fig. 8 System's response to $3 \mathrm{MW}$ regulation signal.

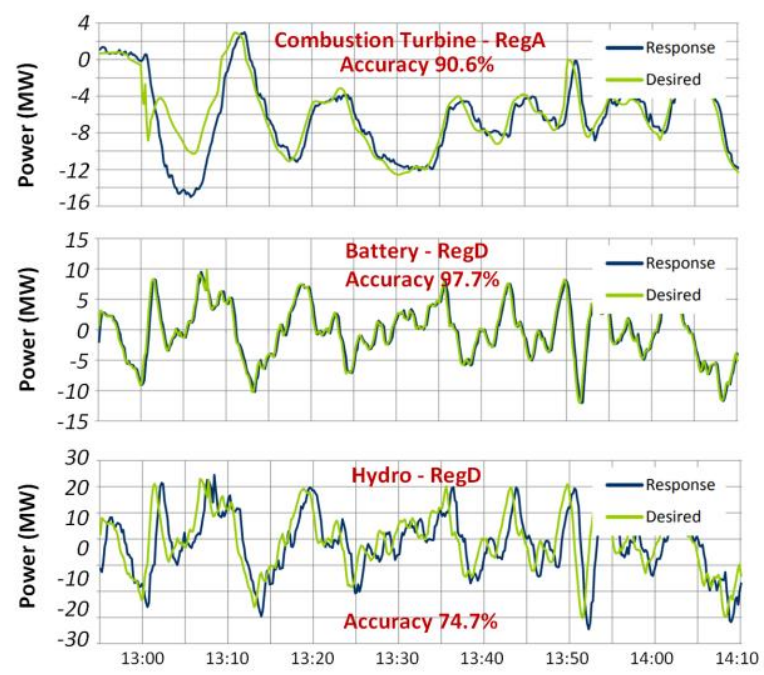

Fig. 9 System's SoC range for regulation profile

\section{KEY FINDINGS AND PROSPECTS}

\section{A. Frequency Regulation and Response}

It has been commonly recognized that with the increasing penetration of power electronic converters and renewable energy sources, system stability has become a critical issue requiring advanced grid services. Fast frequency responses and inertia response are the two major solutions with regard to enhancing grid stability and reliability. The emerging new services include EFR from UK, FFR from Ireland and Australia, RegD signal from PJM, US. These services have been designed with consideration for wider grid-scale ESS adoption, e.g.:

- The EFR has specialized envelope design in order to reduce ESS operational cost and enable ESS selfmanagement (SoC balancing).

- $\quad$ The FERC Order 755 and 784 have opened the ancillary market to ESS by involving additional performance score and compensation.

- The conditional neutral design of RegD signal helps the overall energy balance within a certain period.
However, the design of the services need further improvement considering, for example, the following aspects:

- There is still lack of understanding of grid behavior with high penetration of power electronic devices, especially their influence over grid stability, responses to fault conditions, the stronger coupling between frequency and voltage, and so on. A good understanding of the above questions is the key to design a useful service.

- The frequency dynamics is becoming local, as a result the definition, measurement and detection of frequency event need to be extended and refined.

- Frequency services can be further classified to enable application of versatile technology solutions and expand the service market. An example is the EFR in UK, which require both fast response (1s) and long duration (15min). It limits the application of potentially promising solutions like super-capacitors which are energy critical.

\section{B. The Role and Definition of ESS}

To expand the application of grid-scale ESSs, improvement is still required in the following aspects:

- Clear definition and differentiation of ESS with other generation facilities, relieve over levy and regulation of ESS [66]. Treat ESS as a subset of flexibility assets, for the grid, rather than a subset of generation assets due to the diverse applications of ESS.

- $\quad$ Re-value ESS from system operators when considering system expansion and planning, update system planning tools with regard to ESS benefits and grid impact.

- $\quad$ By recognizing the benefits to grid stability, safety and system operational cost reduction, new market incentives and increased ESS service payment are to be implemented for fast cost recovery.

- $\quad$ Continuous efforts on grid-scale ESS trials and projects to develop a mature service market, clarify the business model and identify key challenges.

Recent research also throw emphasis on the design and control issues of ESS with multi-sources [48], [67], [68], techno-economic benefits [69][81] for these new services.

\section{ROCOF and Inertia Response}

The new trend of grid services includes inertia response aiming to mitigate the high ROCOF caused by increasing penetration of non-synchronous generators and low grid inertia. To mitigate high ROCOF, a faster response is needed. However, the ROCOF measurement and detection has an inherent trade-off between measurement length and measurement accuracy. A longer period of measurement window (2-100 cycles, 50-500ms) can reduce the false detection of frequency event, while the faster response requirement asks for shorter response time.

In addition, false triggering of frequency response can also be caused by short-circuit fault or power quality issues, since distorted voltage waveform affects the accuracy of frequency measurement. Further investigation and coordination of various grid services is required in order to deliver a reliable service to the grid.

From the control perspective, VSM type of controls have 
promising features for ROCOF mitigation and grid stabilization. However, there are still challenges on the voltagestiff control and transient current limitation. From the planning perspective, the cost evaluation, sizing and positioning of ESSs need further investigations.

\section{New Solutions}

Besides energy storage, other inverter interfaced energy resources are also potential providers for frequency and inertia response. Thus, on one hand, the grid codes and regulations are trying to design new services to accommodate mass energy storage applications, while on the other hand, these services have to be technology neutral in order to minimize the cost and encourage a versatile market.

Static Compensator (STATCOM) with power intensive super-capacitors is considered one of the promising devices to provide inertia for frequency and voltage support e.g. Siemens SVC PLUS ES [70]. ABB along with SP Energy Networks is implementing a 4-year project Phoenix to demonstrate a sustainable design, deployment and operational control of a synchronous condenser with a static compensator. The objective is to mitigate the issues UK National Grid is facing, including reduced inertia, low short-circuit power and limited voltage control. The synchronous condenser, thanks to its rotating mass and overloading capability, is able to boost system inertia (although quite limited compared to converter interfaced storage) and enhance system short-circuit power level; the STATCOM, on the other hand, reacts fast in case of voltage and power quality issues.

Furthermore, the design, sizing and positioning philosophy of FFR or SIR type of devices need to be further investigated. Apart from power and energy requirements, other criteria should also be considered e.g. network inertia, network power level, network topology, maximum ROCOF, frequency dynamical feature, number of measurable event (pre-/postfault) per day/week/month, and so on.

From the review of energy storage devices, it is also found that devices are capable to response within few milliseconds but do not have high power density which is required for fast frequency response. Thus, the hybrid ESS with a combination of high power and high energy density devices, operating in active control mode could be very good solution for the new grid services [71], [72]. Power sharing methods in hybrid ESS play an important role in enhancing the battery lifetime as well [73]. The solutions can also be operated in multiple service mode [74].

\section{CONCLUDING REMARKS}

This paper provides an overview of the connection requirements, design considerations, service characteristics and real-world implementation of grid-scale ESS for frequency response provision. Although a number of barriers still exist, system operators in many countries are making effort to design new frequency services, market rule adjustment and project trials in order to encourage business investment and applications. Three representative examples, Enhanced Frequency Response from National Grid UK, Fast Frequency
Response from EirGrid Ireland and Dynamic Regulation Signal from PJM US are introduced in detail as example projects. The major findings are summarized and prospects are discussed.

\section{APPENDIX}

Typically, there exist various requirements related to ESS grid connection and frequency service provision, commonly contained within an international standard or national/regional grid code, where generators must comply with - both prior to initial connection, and while operational, namely grid interconnection requirements (GIR) and system operation practice (SOP), respectively [14]. The entities responsible for creating and enforcing these standards can vary across regions, e.g. Institute of Electrical and Electronics Engineers (IEEE), North America Electric Reliability Corporation (NERC) and European Network of Transmission System Operators for Electricity (ENTSO-E), etc. They usually provide a system wide minimum standard applicable to all regions. In addition to that, the regional TSOs can also have dedicated grid codes which meet the minimum standards while take into account regional features. The objective of this section is to provide an overview and comparison of all the grid standards applicable to ESS interconnection and fast frequency service provision.

\section{A. IEEE 1547-2018 [75]}

IEEE 1547 establishes criteria and requirements for interconnection of distributed resources with EPS. It involves requirements on distributed resources performance, operation, testing, safety and maintenance. These requirements are applicable to all technologies including fuel cells, photovoltaics, dispersed generation and energy storage.

The previous version of IEEE 1547 (IEEE 1547-2003) had limited content related to voltage regulation, voltage and frequency responses to area EPS abnormal conditions. Also had no clause on frequency response or active power support, and only the response to abnormal frequency conditions is stated. In comparison, IEEE 1547-2018 has clearly defined the frequency-droop (frequency response) specifications as given in Table I (row 1).

\section{B. ENTSO-E Network Code, Europe}

The ENTSO-E Network Code for grid connection requirements (NC-RfG) [11] aims to set out clear and objective requirements for Power Generating Modules, including both Synchronous Power Generating Modules and Power Park Modules (a unit or ensemble of units non-synchronously connected or connected through power electronics to a system), for grid connection in order to contribute to non-discrimination, effective competition and the efficient functioning of the internal electricity market and to ensure system security.

NC-RfG classifies the type and significance of generators according to their maximum capacity. The detailed categories are not repeated here but can be found in [11]. Although there is no classification for ESS, it can be considered as a Power Park Module following the general requirements classified according to power size, such the ones defined in Irish Grid Code [76].

NC-RfG also defines a set of frequency regulation 
requirements. A frequency sensitive mode is set, and within the range of which generators must respond to frequency deviation according to a preset droop profile. The frequency response shall be activated as fast as possible.

The full active power frequency response requires $1.5-10 \%$ ramp, 2-sec reaction and full service provision within 30-sec. The detailed requirements from ENTSO-E are also collected in Table I (row 7).

\section{NERC and FERC, United States}

The most critical standard regarding PFR in US is NERC BAL-003-1 [77]. This standard requires that each Balancing Authority (BA) annually satisfies a minimum Frequency Response Measure in order to ensure that it is capable of avoiding Under Frequency Load Shedding for a specified loss of generation. The specific details regarding how BAs meet this target is left to the BAs themselves rather than directed by NERC. NERC has, however, outlined recommended speed governor settings for each of the three U.S. interconnections that support compliance with BAL-003-1.

The Order 755 [78] is proposed by the commission to remedy undue discrimination in the procurement of frequency regulation in the organized wholesale electricity markets and ensure that frequency regulation service providers receive just and reasonable and not unduly discriminatory or preferential rates. This was extended by Federal Energy Regulatory Commission (FERC) Order 784 [79] on 18 July 2013, which required each public utility transmission provider to take into account the speed and accuracy of regulation resources in its determination of reserve requirements for regulation and frequency response service. Furthermore, the FERC Order 842 requires the all the PFR participants have to deliver timely response and sustained until the frequency is back into their deadband range. No specific number is given for either the response time or duration, but a minimum 12-month rolling average initial PFR performance and sustained PFR performance of 0.75 is required [80].

Conventional services for some of the US regions are given in Table I (row 2-5).

\section{National Grid, United Kingdom}

The National Grid in UK is a member of ENTSO-E and mandates that all grid connected generators subject to the Grid Code, including asynchronously connected resources, are capable of providing PFR. Connection requirements [81] are given in Table II (row 7). A market mechanism is adopted based on which the generators (or demand response resources in Firm Frequency Response) submit mandatory bids for capacity reservation. Recently, a new Enhanced Frequency Response (EFR) service is procured by National Grid requiring service tenders provide a modulated frequency response activated within 1s [20]. EFR is designed with an ultrafast response in order to reduce ROCOF and maintain grid stability.

\section{E. ENERGINET, Denmark}

The TSO of Denmark, ENERGINET, has defined the operational rules for grid connected battery plants in 2017 [82]. Two types of frequency responses are used namely Limited
Frequency Sensitive Mode-Overfrequency (LFSM-O) and Limited Frequency Sensitive Mode-Underfrequency (LFSM$\mathrm{U})$. For battery plants smaller than $1.5 \mathrm{MW}$, they are obliged to provide LFSM-O, while for those above $1.5 \mathrm{MW}$, they must provide both LFSM-O and LFSM-U. The details are collected in Table I [82].

\section{F. State Grid Corporation of China, China}

The State Grid Corporation of China has defined dedicated Technical Guideline (Q/GDW 564-2010) [83] and Operation \& Control Specification (Q/GDW 696-2011) [84] for grid connection of ESS. Q/GDW 564-2010 requires that 1) the ESS should respond to frequency event according to specified frequency ranges, and 2) the ESS is able to control its reactive power (power factor between 0.98 lead to $0.98 \mathrm{lag}$ ) following set-points from operators in order to regulate grid voltage.

Q/GDW 696-2011 defines the operational requirements of ESS in providing frequency response in normal operation range (grid frequency between 49.5 50.2 Hz):

- Following the preset operating curve approved by system operator with control error less than $10 \%$

- Active power response time within $200 \mathrm{~ms}$

- Provide frequency response such that: i) $49.5 \sim 49.8 \mathrm{~Hz}$, ESS discharges with response time less than 200ms; ii) frequency higher than $50.2 \mathrm{~Hz}$, ESS charges with response time less than $200 \mathrm{~ms}$; iii) full power continuous operation no less than 2 minutes.

Q/GDW 696-2011 also specifies that when active power (frequency response) and reactive power (voltage response) are required at the same time, the frequency response has higher priority.

\section{G. EirGrid, Ireland and SONI, Northern Ireland}

The Grid Codes of Ireland [76] has been modified to include PPMs. Battery storage units are treated as PPM units. They must provide all capabilities as required in Grid Code. Battery generation will be considered like any other generator, and battery demand will be treated like other demand customers and therefore additional definitions are required for this PPM technology type. This type of storage is similar to Pumped Storage Plants where there are two modes of operation. So the terminology for Energy Storage devices has been kept consistent with that for pumped storage plants.

The generators connection and operating capabilities are also specified in the Grid Codes of Ireland, requiring generators to provide support in different conditions and frequency ranges. Dispatch strategies are designed according to the size at the point of connection [76].

Besides, the main TSOs in Ireland (EIRGRID and SONI) have created a DS3 program [4] as mentioned before. A number of new services are proposed, among which the Synchronous Inertia Response (SIR) and FFR are closely related with frequency regulation and ESS could play a significant role. SIR asks for immediate provision of active power following frequency disturbances in order to limit the ROCOF. In addition to SIR, the FFR service requires a fast (within $2 \mathrm{~s}$ ) and continuous supply of power (at least $8 \mathrm{~s}$ ) after frequency deviation. Important parameters for this new service are also 
given in Table II. Details about these two services are given in Section IV.

Along with these, the important values for some other active regions and countries such as Texas (US) [85], New England (US) [86], Ontario (Canada) [87], PJM (US) [88], Finland [89], Brazil [90], Italy [91], New Zealand [92], Singapore [93] and South Africa [94][95] are also given in Table I.

\section{REFERENCES}

[1] U. National Grid, "Future Energy Scenarios," 2017.

[2] S. Bradbury, "STORAGE BUSINESS MODELS IN THE GB MARKET," 2014.

[3] M. Bell et al., "Power sector scenarios for the fifth carbon budget Other members of the Secretariat who contributed to this report," 2015.

[4] Eirgrid and SONI, "DS3: Frequency Control Workstream 2015," 2015.

[5] D. Lew et al., "Technology Capabilities for Fast Frequency Response," 2017.

[6] "Enhanced Frequency Control Capability (EFCC) National Grid Battery Storage Investigation Report-November 2015."

[7] The Electricity Storage Network, "DEVELOPMENT OF ELECTRICITY STORAGE IN THE NATIONAL INTEREST," 2014.

[8] Renewable Energy Association, "Energy Storage in the UK - An Overview," 2015.

[9] Bird\&Bird, "The role of energy storage in the UK electricity system," 2014.

[10] Workstream 6 of the Smart Grid Forum, "The customer-focused smart grid: Next steps for regulatory policy and commercial issues in GB Report of Workstream Six of the Smart Grid Forum, 2015,” 2015.

[11] "COMMISSION REGULATION (EU) 2016/631 - of 14 April 2016 - establishing a network code on requirements for grid connection of generators," 2016.

[12] G. Kou, P. Markham, S. Hadley, T. King, and Y. Liu, "Impact of Governor Deadband on Frequency Response of the U.S. Eastern Interconnection,” IEEE Trans. Smart Grid, vol. 7, no. 3, pp. 1368-1377, May 2016.

[13] J. Undrill, "Primary Frequency Response and Control of Power System Frequency," 2018.

[14] C. Roberts, "Review of International Grid Codes," 2018.

[15] Q. Hong et al., "Fast frequency response for effective frequency control in power systems with low inertia," 2018.

[16] H. Thi, "General rights Frequency Characterization and Control for Future Low Inertia Systems."

[17] F. Milano, F. Dorfler, G. Hug, D. J. Hill, and G. Verbic, "Foundations and Challenges of Low-Inertia Systems (Invited Paper)," in 2018 Power Systems Computation Conference (PSCC), 2018, pp. 1-25.

[18] X. Luo et al., "Review of Voltage and Frequency Grid Code Specifications for Electrical Energy Storage Applications," Energies, vol. 11, no. 5, p. 1070, Apr. 2018.

[19] PJM, "Implementation and Rationale for PJM's Conditional Neutrality Regulation Signals," 2017.

[20] "ENHANCED FREQUENCY RESPONSE Invitation to tender for prequalified parties," 2016

[21] "DS3 System Services Protocol-Regulated Arrangements DS3 System Services Implementation Project," 2017.

[22] "National Electricity Transmission System Security and Quality of Supply Standard," 2019.

[23] J. Richardson and M. Bennett, "RM16-6- Essential Reliability Services and the Evolving Bulk-Power System-Primary Frequency Response."

[24] "Enhanced Frequency Response Frequently Asked Questions."

[25] J. Riesz and J. Palermo, "INTERNATIONAL REVIEW OF FREQUENCY CONTROL ADAPTATION Australian Energy Market Operator," 2016.

[26] H. Thiesen, C. Jauch, and A. Gloe, "Design of a System Substituting Today's Inherent Inertia in the European Continental Synchronous Area," Energies, vol. 9, no. 8, p. 582, Jul. 2016.

[27] M. Farhadi and O. Mohammed, "Energy Storage Technologies for HighPower Applications," IEEE Trans. Ind. Appl., vol. 52, no. 3, pp. 19531961, May 2016.

[28] K. Li and K. J. Tseng, "Energy efficiency of lithium-ion battery used as energy storage devices in micro-grid," in IECON 2015 - 41st Annual Conference of the IEEE Industrial Electronics Society, 2015, pp. 005235-005240.
[29] G. Delille, B. Francois, and G. Malarange, "Dynamic Frequency Control Support by Energy Storage to Reduce the Impact of Wind and Solar Generation on Isolated Power System's Inertia," IEEE Trans. Sustain. Energy, vol. 3, no. 4, pp. 931-939, Oct. 2012.

[30] V. Knap, R. Sinha, M. Swierczynski, D.-I. Stroe, and S. Chaudhary, "Grid inertial response with Lithium-ion battery energy storage systems," in 2014 IEEE 23rd International Symposium on Industrial Electronics (ISIE), 2014, pp. 1817-1822.

[31] M. Yue and X. Wang, "Grid Inertial Response-Based Probabilistic Determination of Energy Storage System Capacity Under High Solar Penetration," IEEE Trans. Sustain. Energy, vol. 6, no. 3, pp. 1039-1049, Jul. 2015.

[32] V. Knap, S. K. Chaudhary, D.-I. Stroe, M. Swierczynski, B.-I. Craciun, and R. Teodorescu, "Sizing of an Energy Storage System for Grid Inertial Response and Primary Frequency Reserve," IEEE Trans. Power Syst., vol. 31, no. 5, pp. 3447-3456, Sep. 2016.

[33] A. Oudalov, D. Chartouni, and C. Ohler, "Optimizing a Battery Energy Storage System for Primary Frequency Control,” IEEE Trans. Power Syst., vol. 22, no. 3, pp. 1259-1266, Aug. 2007.

[34] M. Kintner-Meyer et al., "National Assessment of Energy Storage for Grid Balancing and Arbitrage: Phase 1, WECC,” 2012.

[35] M. R. Aghamohammadi and H. Abdolahinia, "A new approach for optimal sizing of battery energy storage system for primary frequency control of islanded Microgrid," Int. J. Electr. Power Energy Syst., vol. 54, pp. 325-333, Jan. 2014.

[36] S. Wogrin and D. F. Gayme, "Optimizing Storage Siting, Sizing, and Technology Portfolios in Transmission-Constrained Networks," IEEE Trans. Power Syst., vol. 30, no. 6, pp. 3304-3313, Nov. 2015.

[37] Y. J. A. Zhang, C. Zhao, W. Tang, and S. H. Low, "Profit-Maximizing Planning and Control of Battery Energy Storage Systems for Primary Frequency Control," IEEE Trans. Smart Grid, vol. 9, no. 2, pp. 712-723, Mar. 2018.

[38] B. K. Poolla, D. Gross, and F. Dorfler, "Placement and Implementation of Grid-Forming and Grid-Following Virtual Inertia and Fast Frequency Response," IEEE Trans. Power Syst., pp. 1-1, 2019.

[39] B. K. Poolla, D. Groß, T. Borsche, S. Bolognani, and F. Dörfler, "Virtual Inertia Placement in Electric Power Grids," Springer, New York, NY, 2018, pp. 281-305.

[40] Y. Zhu, C. Liu, K. Sun, D. Shi, and Z. Wang, "Optimization of Battery Energy Storage to Improve Power System Oscillation Damping," IEEE Trans. Sustain. Energy, pp. 1-1, 2018.

[41] S. Bose, D. F. Gayme, U. Topcu, and K. M. Chandy, "Optimal placement of energy storage in the grid," in 2012 IEEE 51st IEEE Conference on Decision and Control (CDC), 2012, pp. 5605-5612.

[42] M. G. Hoffman, A. Sadovsky, M. C. Kintner-Meyer, and J. G. Desteese, "Analysis Tools for Sizing and Placement of Energy Storage in Grid Applications A Literature Review," 2010.

[43] Y. G. Rebours, D. S. Kirschen, M. Trotignon, and S. Rossignol, “A Survey of Frequency and Voltage Control Ancillary Services-Part I: Technical Features," IEEE Trans. Power Syst., vol. 22, no. 1, pp. 350 357, Feb. 2007.

[44] "P1-Policy 1: Load-Frequency Control and Performance [C]."

[45] "Network Code on Load-Frequency Control and Reserves in line with the ACER Framework Guidelines on Electricity System Operation," 2013.

[46] "FAST FREQUENCY RESPONSE IN THE NEM," 2017.

[47] S. Bradbury, J. Hayling, P. Papadopoulos, and N. Heyward, "Smarter Network Storage Electricity Storage in GB: SNS 4.7 Recommendations for regulatory and legal framework (SDRC 9.5)."

[48] F. Sanchez, J. Cayenne, F. Gonzalez-Longatt, and J. L. Rueda, "Controller to enable the enhanced frequency response services from a multi-electrical energy storage system," IET Gener. Transm. Distrib., vol. 13, no. 2, pp. 258-265, Jan. 2019.

[49] M. Dreidy, H. Mokhlis, and S. Mekhilef, "Inertia response and frequency control techniques for renewable energy sources: A review," Renew. Sustain. Energy Rev., vol. 69, pp. 144-155, Mar. 2017.

[50] G. Delille, B. François, S. Member, and G. Malarange, "Dynamic Frequency Control Support by Energy Storage to Reduce the Impact of Wind and Solar Generation on Isolated Power System's Inertia," IEEE Trans. Sustain. ENERGY, vol. 3, no. 4, 2012.

[51] M. ; Altin, J. C. Kuhlmann, K. ; Das, and A. D. Hansen, "Optimization of Synthetic Inertial Response from Wind Power Plants," Citation, vol. 11, no. 5, 2019.

[52] R. Eriksson, N. Modig, and K. Elkington, "Synthetic inertia versus fast frequency response: a definition," IET Renew. Power Gener., vol. 12, 
no. 5, pp. 507-514, Apr. 2018.

[53] F. M. Gonzalez-Longatt and S. M. Alhejaj, "Enabling inertial response in utility-scale battery energy storage system," in 2016 IEEE Innovative Smart Grid Technologies - Asia (ISGT-Asia), 2016, pp. 605-610.

[54] A. Bonfiglio, F. Gonzalez-Longatt, and A. R. Procopio, "Integrated Inertial and Droop Frequency Controller for Variable Speed Wind Generators."

[55] H.-P. Beck and R. Hesse, "Virtual synchronous machine," in 2007 9th International Conference on Electrical Power Quality and Utilisation, 2007, pp. 1-6.

[56] Q.-C. Zhong and G. Weiss, "Synchronverters: Inverters That Mimic Synchronous Generators," IEEE Trans. Ind. Electron., vol. 58, no. 4, pp. 1259-1267, Apr. 2011.

[57] L. Zhang, L. Harnefors, and H.-P. Nee, "Power-Synchronization Control of Grid-Connected Voltage-Source Converters," IEEE Trans. Power Syst., vol. 25, no. 2, pp. 809-820, May 2010.

[58] M. Kazemi, H. Zareipour, N. Amjady, W. D. Rosehart, and M. Ehsan, "Operation Scheduling of Battery Storage Systems in Joint Energy and Ancillary Services Markets," IEEE Trans. Sustain. Energy, vol. 8, no. 4, pp. 1726-1735, Oct. 2017.

[59] B. Olek and M. Wierzbowski, "Local Energy Balancing and Ancillary Services in Low-Voltage Networks With Distributed Generation, Energy Storage, and Active Loads," IEEE Trans. Ind. Electron., vol. 62, no. 4, pp. 2499-2508, Apr. 2015

[60] B. Cheng and W. Powell, "Co-optimizing Battery Storage for the Frequency Regulation and Energy Arbitrage Using Multi-Scale Dynamic Programming," IEEE Trans. Smart Grid, pp. 1-1, 2016.

[61] A. Perez, R. Moreno, R. Moreira, M. Orchard, and G. Strbac, "Effect of Battery Degradation on Multi-Service Portfolios of Energy Storage," IEEE Trans. Sustain. Energy, vol. 7, no. 4, pp. 1718-1729, Oct. 2016.

[62] J. W. Shim, G. Verbic, N. Zhang, and K. Hur, "Harmonious Integration of Faster-Acting Energy Storage Systems Into Frequency Control Reserves in Power Grid With High Renewable Generation," IEEE Trans. Power Syst., vol. 33, no. 6, pp. 6193-6205, Nov. 2018.

[63] V. Calderaro, V. Galdi, F. Lamberti, and A. Piccolo, "Co-located storage systems with renewable energy sources for voltage support in distribution networks," in 2015 IEEE Power \& Energy Society General Meeting, 2015, pp. 1-5.

[64] East Penn Manufacturing Co, "Final Technical Performance Report Grid-Scale Energy Storage Demonstration of Ancillary Services Using the UltraBattery," 2015.

[65] T. Lee, "ENERGY STORAGE IN PJM EXPLORING FREQUENCY REGULATION MARKET TRANSFORMATION," 2017.

[66] "EUROPEAN ENERGY STORAGE TECHNOLOGY DEVELOPMENT ROADMAP 2017 UPDATE Joint EASE/EERA recommendations for a."

[67] M. Bahloul and S. K. Khadem, "Design and control of energy storage system for enhanced frequency response grid service," in 2018 IEEE International Conference on Industrial Technology (ICIT), 2018, pp. $1189-1194$.

[68] V. Knap, S. K. Chaudhary, D.-I. Stroe, M. Swierczynski, B.-I. Craciun, and R. Teodorescu, "Sizing of an Energy Storage System for Grid Inertial Response and Primary Frequency Reserve," IEEE Trans. Power Syst., vol. 31, no. 5, pp. 3447-3456, Sep. 2016.

[69] D. M. Greenwood, K. Y. Lim, C. Patsios, P. F. Lyons, Y. S. Lim, and P. C. Taylor, "Frequency response services designed for energy storage," Appl. Energy, vol. 203, pp. 115-127, Oct. 2017.

[70] E. Spahic, C. P. Susai Sakkanna Reddy, M. Pieschel, and R. Alvarez, "Multilevel STATCOM with power intensive energy storage for dynamic grid stability - frequency and voltage support," in 2015 IEEE Electrical Power and Energy Conference (EPEC), 2015, pp. 73-80.

[71] Y. Kim, V. Raghunathan, and A. Raghunathan, "Design and Management of Battery-Supercapacitor Hybrid Electrical Energy Storage Systems for Regulation Services,” IEEE Trans. Multi-Scale Comput. Syst., vol. 3, no. 1, pp. 12-24, Jan. 2017.

[72] D. M. Greenwood, K. Y. Lim, C. Patsios, P. F. Lyons, Y. S. Lim, and P. C. Taylor, "Frequency response services designed for energy storage," Appl. Energy, vol. 203, pp. 115-127, Oct. 2017.

[73] M. Bahloul and S. K. Khadem, "Impact of power sharing method on battery life extension in HESS for grid ancillary services," IEEE Trans. Energy Convers., pp. 1-1, 2018.

[74] R. Capo-Misut, R. S. Munoz-Aguilar, J. Rocabert, J. I. Candela, and P. Rodriguez, "Control of energy storage system integrating electrochemical batteries and SC for grid-connected applications," in 2016 IEEE Energy Conversion Congress and Exposition (ECCE), 2016, pp. $1-6$.

[75] "IEEE Standard for Interconnection and Interoperability of Distributed Energy Resources with Associated Electric Power Systems Interfaces," IEEE Std 1547-2018, pp. 1-138.

[76] EIRGRID, “Grid Code v6 EirGrid Grid Code," 2015.

[77] NERC, "BAL-003-1.1 Frequency Response and Frequency Bias Setting," 2017.

[78] FERC, "RM11-7-000 Frequency Regulation Compensation in the," 2011.

[79] FERC, "Third-Party Provision of Ancillary Services; Accounting and Financial Reporting for New Electric Storage Technologies," 2013.

[80] NERC, "BAL-001-TRE-1-Primary Frequency Response in the ERCOT Region."

[81] National Grid (UK), "THE GRID CODE (UK)," 2017.

[82] ENERGINET, "Technical regulation 3.3.1 for battery plants," 2017.

[83] State Grid Corporation of China, Q/GDW 564-2011, Technical guideline for electric energy storage system interconnecting with distribution network. 2012.

[84] State Grid Corporation of China, "Q/GDW 696-2011, Operation and control specification for electric energy storage system interconnecting with distribution network," 2012.

[85] ERCOT, "Nodal Operating Guide," 2018.

[86] ISO-NE, "Operating procedure," 2017.

[87] IESO Canada, "Market Rules.".

[88] PJM, "PJM Generators Operational Requirement," 2017. .

[89] M. Kuivaniemi, N. Modig, and R. Eriksson, "FCR-D design of requirements," 2017.

[90] Operador Nacional do Sistema Elétrico, "PROCEDIMENTOS DE REDE (Networking Procedures)," 2018.

[91] Terna, "The code for transmission, dispatching, developing and security of the grid (Annex A15 and A73)," 2014. .

[92] Electricity Authority Te Mano Hiko, "Normal Frequency Management Strategic Review," 2017.

[93] Energy Market Authority, "Singapore Electricity Market Rules Appendix 6J," 2017.

[94] "The South African Grid Code-Network Code Rev The South African Grid Code The Network Code Version 7.0 2 The South African Grid Code-Network Code Rev."

[95] "GRID CONNECTION CODE FOR RENEWABLE POWER PLANTS (RPPs) CONNECTED TO THE ELECTRICITY TRANSMISSION SYSTEM (TS) OR THE DISTRIBUTION SYSTEM (DS) IN SOUTH AFRICA."

\section{BIOGRAPHIES}

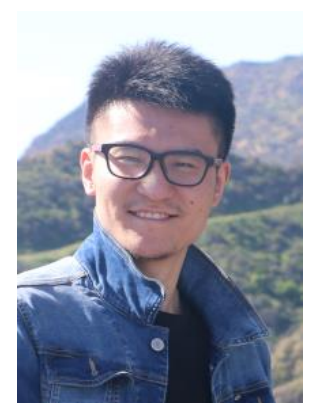

Lexuan Meng (S'2012, M'2015) received the B.S. degree in Electrical Engineering and M.S. degree in Electrical Machine and Apparatus from Nanjing University of Aeronautics and Astronautics (NUAA), Nanjing, China, in 2009 and 2012, respectively. In 2015, he received the Ph.D. degree in Power Electronic Systems from Institute of Energy Technology, Aalborg University, Denmark. 2015-2017, he was a postdoc in Aalborg University working with Maersk Drilling on flywheel energy storage system for marine applications. 2017-2018, he was a research engineer in Power Network Demonstration Centre, Glasgow, UK responsible for projects on grid scale energy storage systems. He is now an R\&D engineer in FACTS, Power Grid division, ABB, Sweden, with main responsibility on FACTS controllers and grid energy storage systems. His research interests are in power electronic systems and devices for future grid applications. 


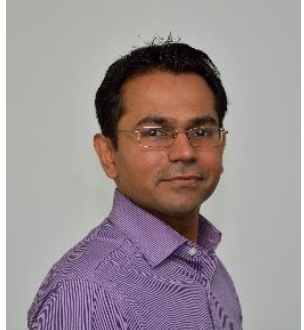

Jawwad Zafar was born in Pakistan. $\mathrm{He}$ graduated with a Bachelor's degree in Industrial Electronics from the NED University of Engineering and Technology, Karachi.

Dr Zafar received a Masters degree in Power Engineering from Chalmers University of Technology, Sweden in Electric Power Engineering and a PhD from Universite Libre de Bruxelles, Belgium.

His employment experience includes public R\&D centres, universities and consultancy. His interest is in the control and impact of converter interfaced devices on the electricity network.

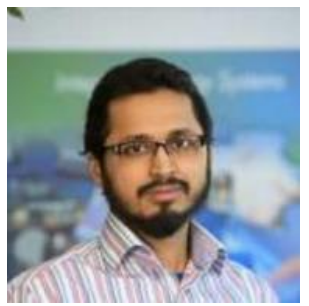

Shafiuzzaman K Khadem (S'09-M'13) received the B.Sc and M.Sc degrees in Applied Physics and Electronics from University of Dhaka, Bangladesh, and PhD in Electrical and Electronic Engineering from Technology University Dublin, Ireland.

At present, he is a Senior Researcher and lead the Embedded and Distributed Generation systems (EDGE) research group in the International Energy Research Centre (IERC). Prior to that, he also served in different research and academic positions in universities, international organizations and industries in multi-disciplinary teams. He also led the Electricity Transmission System Leadership Training Course for top management staff of the newly created Electricity Sector Regulatory Agency (ARSEL) - Cameroon (World Bank sponsored). He is research active in smart grid, intelligent energy systems integration, such as microgrids, virtual power plant, converter design, active power filtering.

Dr Khadem received recognitions from different institutions including HEA (IE), ICTP (IT), EU Erasmus (UK), DIT (IE), IRCSET (IE), IEEE (USA). He is a member of the research grant evaluation panel H2020 MSCA (IF). He is also a member of the IEEE power and energy society and smart grid community.

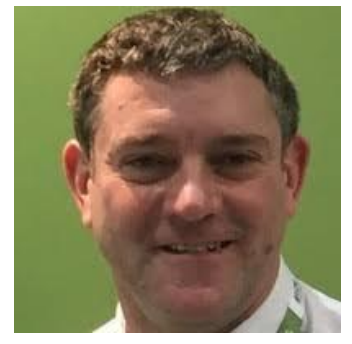

Alan Collinson For the past four years Alan has been part of the Commercial and Innovation Group at SP Energy Networks.

He has worked on several innovation projects, focusing on Smart Grid technologies, including Network Visibility, Community Energy, Energy Storage and the DSO transition.

Alan previously worked in the SP Manweb Network Design and Planning department, responsible for $33 \mathrm{kV}$ and $132 \mathrm{kV}$ network reinforcement, including the major regeneration of the Liverpool City Centre and the connection of many large on-shore wind farms in North and Mid Wales. Alan's first involvement in utility-scale electrical energy storage stretches back to the 1990's, with his work with the International Energy Agency and the formation of the UK National Team on Energy Storage, which included the inaugural international energy storage conference-EESAT ' 98 , in Chester. He subsequently became involved in the DNO-led Energy Storage Operators Forum.

Alan has been involved in many industry forums and ENA working groups and is currently working within the ENA's "Open Networks" DSO project.

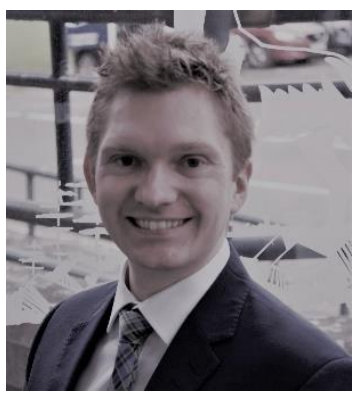

Kyle Murchie was born in Glasgow in Scotland, United Kingdom, on February 25 1990. He graduated from Mearns Castle High School, Newton Mearns, and studied at the University of Strathclyde.

His employment experience includes Scottish and Southern Electricity Networks, Electricity North West, TNEI Group and UK Power Networks (formerly EDF Energy Networks). His special fields of interest included Power System Economics and the wider transition to a Low Carbon Economy. Kyle Murchie is currently Situated within the DSO and Innovation team at Scottish and Southern Electricity Networks, in a role encompassing a broad range of projects including but not limited to new NIC, NIA, IRM and Losses Discretionary Reward. Responsibilities include the successful delivery of the distribution Innovation Strategy and the securing of funding for new transmission and distribution innovation concepts. In addition to Innovation Strategy, he is one of the SSEN representatives on the ENA Open Networks Project, leading the TRANSITION, EFFS and FUSION (T.E.F.) interface with the relevant workstreams and National Grid ESO. In February 2019 this role was extended to include all significant GB industry trials. He presently supports the shaping of TRANSITION and its interface with the LEO Project partners to ensure alignment with industry direction and that the Oxfordshire Projects collectively achieve more than their set deliverables, maximising the benefits realised by our stakeholders which most importantly includes consumers.

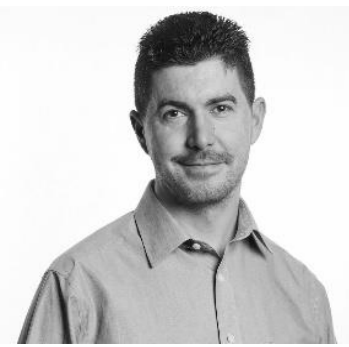

Federico Coffele received the B.Sc. in Electrical Engineering and M.Eng. in Electrical Power Systems from the University of Padova, Italy in 2004 and 2007, respectively. He worked for ABB Power Products in Italy, in the R\&D department, and then he joined the University of Strathclyde, in Glasgow, Scotland, working in the area of protection and control of power distribution networks, power system modelling and simulation. During this period he also worked toward his $\mathrm{PhD}$, which he received from the University of Strathclyde in 2012.

Currently he is the Research and Development Manager of the Power Network Demonstration Centre (PNDC) at the University of Strathclyde, which is a world-class facility with dedicated staff to accelerate the adoption of new, smart technologies within present and future power grids, supporting the increased accommodation of renewable energy, electric vehicles and demand side management.

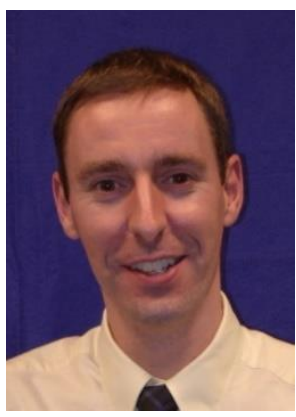

Graeme M. Burt (M'95) received the B.Eng. degree in electrical and electronic engineering, and the Ph.D. degree in fault diagnostics in power system networks from the University of Strathclyde, Glasgow, U.K., in 1988 and 1992, respectively. He is currently a Professor of electrical power systems at the University of Strathclyde where he co-directs the Institute for Energy and Environment, directs the Rolls-Royce University Technology Centre in Electrical Power Systems, and is lead academic for the Power Networks Demonstration Centre (PNDC). In addition, he serves as spokesperson for the board of DERlab e.V., the association of distributed energy laboratories. His research interests include the areas of power system protection and control, distributed energy, hybrid propulsion and experimental validation. 